\title{
Evaluation Criteria of Noninvasive Telemonitoring for Patients With Heart Failure: Systematic Review
}

Troskah Farnia ${ }^{1}$, MSc; Marie-Christine Jaulent ${ }^{1}$, PhD; Olivier Steichen ${ }^{1,2}$, MD, PhD

${ }^{1}$ Laboratoire d'Informatique Médicale et Ingénierie des Connaissances en eSanté, Institut National de la Santé et de la Recherche Médicale, Sorbonne Universités, Université Paris 13, Sorbonne Paris Cité, Paris, France

${ }^{2}$ Department of Internal Medicine, Hôpital Tenon, Assistance Publique-Hôpitaux de Paris, Paris, France

\section{Corresponding Author:}

Olivier Steichen, $\mathrm{MD}, \mathrm{PhD}$

Department of Internal Medicine

Hôpital Tenon

Assistance Publique-Hôpitaux de Paris

4 Rue de la Chine

Paris,

France

Phone: 33156017831

Email: olivier.steichen@aphp.fr

\section{Abstract}

Background: Telemonitoring can improve heart failure (HF) management, but there is no standardized evaluation framework to comprehensively evaluate its impact.

Objective: Our objectives were to list the criteria used in published evaluations of noninvasive HF telemonitoring projects, describe how they are used in the evaluation studies, and organize them into a consistent scheme.

Methods: Articles published from January 1990 to August 2015 were obtained through MEDLINE, Web of Science, and EMBASE. Articles were eligible if they were original reports of a noninvasive HF telemonitoring evaluation study in the English language. Studies of implantable telemonitoring devices were excluded. Each selected article was screened to extract the description of the telemonitoring project and the evaluation process and criteria. A qualitative synthesis was performed.

Results: We identified and reviewed 128 articles leading to 52 evaluation criteria classified into 6 dimensions: clinical, economic, user perspective, educational, organizational, and technical. The clinical and economic impacts were evaluated in more than $70 \%$ of studies, whereas the educational, organizational, and technical impacts were studied in fewer than 15\%. User perspective was the most frequently covered dimension in the development phase of telemonitoring projects, whereas clinical and economic impacts were the focus of later phases.

Conclusions: Telemonitoring evaluation frameworks should cover all 6 dimensions appropriately distributed along the telemonitoring project lifecycle. Our next goal is to build such a comprehensive evaluation framework for telemonitoring and test it on an ongoing noninvasive HF telemonitoring project.

(J Med Internet Res 2018;20(1):e16) doi: 10.2196/jmir.7873

\section{KEYWORDS}

telemedicine; outcome and process assessment (health care); program evaluation; heart failure

\section{Introduction}

Heart failure (HF) affects 26 million people worldwide, incurring direct and indirect costs of more than US $\$ 100$ billion per year $[1,2]$. HF causes $1 \%$ to $2 \%$ of all hospitalizations, representing a major burden for patients and the health care system [3]. Number of hospitalizations is a marker of disease instability, and studies have shown that HF management can reduce this number [4].

Telemonitoring is a branch of telemedicine defined as the use of communication technologies to monitor and transmit data on the health status of patients to distant care providers $[5,6]$. It differs from teleconsultation, where there is a real-time interactive video or audio consultation between the patient and a distant health care provider. It also differs from tele-expertise, 
where a health care provider presents a patient case and gets advice from a distant colleague through a dedicated system, without direct patient involvement, in real or deferred time.

Systematic reviews of telemonitoring projects have shown reduced hospitalization rates for acute HF [7-9]. Both the European Society of Cardiology and the American Heart Association support the use of telemonitoring to improve the care of HF patients [10,11]. HF telemonitoring can involve the use of invasive or noninvasive monitoring devices. Invasive devices are implanted in the body, and data transmission is not controlled by the patient. Noninvasive devices, like weight scales or blood pressure monitors, are used, mostly by the patient, to self-monitor physiological measurements, signs, or symptoms of the disease.

The information flow is much more intricate with noninvasive than with invasive telemonitoring. First, human action is needed to handle noninvasive telemonitoring devices whereas monitored data is automatically recorded and sent by invasive telemonitoring devices. Second, patients (or family caregivers) are major actors of the noninvasive telemonitoring process whereas their involvement is minimal with invasive telemonitoring. Third, nurses and primary care physicians are usually involved in the noninvasive telemonitoring process whereas they do not take part in invasive monitoring. Fourth, as a result of these differences, noninvasive HF telemonitoring requires readiness for change, education, and training of patients and caregivers whereas invasive HF telemonitoring does not [8]. Due to these major differences, this review focuses on noninvasive HF telemonitoring.

The development of evaluation criteria for electronic tools is considered to be a critical step by the European Society of Cardiology [10]. Standard evaluation frameworks are useful to encourage systematic evaluation and get conclusive results that can be compared or aggregated across programs, allowing the analysis of determinants of success and failure for efficient resource allocation. Standard evaluation frameworks have been used for the evaluation of teleconsultation and tele-expertise [12-16]. To our knowledge, they have not yet been used for the evaluation of telemonitoring projects. Telemonitoring interventions are complex: they involve many different actors with different backgrounds (health care professional, patients and family, technicians, payers), they use technical devices, and they change the usual process of care. They can impact health care on many levels [17]: patient access to care, health and quality of life, patient and care provider education, family and care provider workload, organization of the patient care pathway, health care costs, and more. A comprehensive telemonitoring evaluation framework therefore needs to be multidimensional.

Our aim was to perform a systematic review of criteria used for the evaluation of noninvasive $\mathrm{HF}$ telemonitoring projects, describe how they are used in evaluation studies, and organize them into a consistent scheme.

\section{Methods}

\section{Information Sources and Eligibility Criteria}

We did not submit a review protocol to a prospective register. We searched Medical Literature Analysis and Retrieval System Online (MEDLINE), Excerpta Medica database (EMBASE), and Web of Science for articles published from January, 1990, to the query date (August 15, 2015) using the queries displayed in Multimedia Appendix 1. The search strategy for each bibliographic database was internally discussed, piloted, and refined by the authors but not submitted for external peer review. We checked reference lists of included articles to identify additional studies. We also took advantage of 3 Cochrane reviews on telemonitoring, published shortly after the last query date of our review, to look for missed studies [18-20].

Articles were eligible if they were original reports of a noninvasive telemonitoring project evaluation study for $\mathrm{HF}$ using explicit evaluation criteria. Articles were excluded if they did not contain original data (reviews, editorials, position papers, etc), were not written in English, focused on other types of telemedicine (teleconsultation, tele-expertise, etc), and if they reported invasive telemonitoring for $\mathrm{HF}$ through implantable devices.

\section{Study Selection and Data Collection}

After eliminating duplicate articles, titles and abstracts were independently screened by 2 readers to exclude obviously irrelevant articles. Discordant classifications between the 2 readers were resolved through discussion. The full text of remaining articles was read by 1 investigator, who applied eligibility and exclusion criteria. The final selection was cross-checked by a second investigator. Characteristics of the telemonitoring project, characteristics of the evaluation process, and evaluation criteria were systematically abstracted by 1 investigator and cross-checked by another. The collected data are reported in Multimedia Appendix 2.

\section{Synthesis of Results}

A preliminary list of broad evaluation dimensions was adapted by 2 investigators from previously published evaluation frameworks for telemedicine [12-16]. This categorization was then iteratively refined to meld the evaluation criteria found in each reviewed study into a consistent scheme.

\section{Results}

\section{Study Selection and Characteristics}

The queries of bibliographic databases identified 328 potentially eligible articles, and we included 128 articles in the review (reference list is in Multimedia Appendix 3). The review flowchart describes the process and reasons for exclusion (Figure 1). Characteristics of the 128 studies are reported in Multimedia Appendix 4, and a summary is presented in Table 1.

Europe and the United States contributed the most to the assessment of $\mathrm{HF}$ telemonitoring (50\% of studies performed in Europe and $41 \%$ in the United States). The first study began in 
1997 in the United States [21]. Europe started to carry out research to assess HF telemonitoring 3 years later [22-24].

\section{Telemonitoring Characteristics}

Some features were highly prevalent across the telemonitoring projects: $80 \%$ were carried out by a cardiology team, and the care providers were most often HF nurses ( $86 \%$ of projects). Patients were actively involved in $100 \%$ of the projects, but the family of the patients, psychologists, and technicians rarely participated. In $75 \%$ of studies, patients were included in the telemonitoring program at discharge from a hospitalization for acute heart failure. The phase of the project lifecycle was clear and identifiable in 125 articles: most of these projects were in the implementation phase (59\%), and no project was part of routine clinical care.

The primary monitored data in the telemonitoring projects were weight, HF symptoms, heart rate, and blood pressure. These data were transmitted via telephone (verbal communication or keypad) or Internet (mobile phone or tablet). If the monitored data fell outside predefined boundaries, a warning was triggered and led to corrective actions. However, these actions were described in only 63 articles (49\% of studies).

\section{Evaluation Dimensions and Criteria}

We retrieved 52 criteria from the 128 studies (Textbox 1) and classified them into 6 main dimensions: economic, clinical, educational, technical, user perspective, and organizational.

Most studies (95\%) covered, at most, 3 dimensions, and none covered all 6 (Multimedia Appendix 5). Clinical and economic dimensions were assessed in over $70 \%$ of studies, whereas the educational, organizational, and technical dimensions were studied in less than $15 \%$ (Table 2).

The evaluation dimensions were not used homogeneously across all phases of project lifecycle. User perceptive was the most often covered dimension in the development phase with clinical and economic dimensions covered most in the later phases (implementation and integration).

Each dimension includes from 2 to 16 criteria (Textbox 1). The total number of criteria used per study ranged from 1 to 11 (Multimedia Appendix 6). The most often used evaluation criteria were cost and resource utilization $(71 \%)$ and quality of life $(51 \%)$ (Table 3). The criteria within the same dimension were also not used homogeneously across all phases of the project lifecycle. Concerning user perspective, for example, ease of use of the devices was more often evaluated in the development phase, whereas satisfaction with care was more often evaluated in the later phases of the project lifecycle (Table 3). 
Figure 1. Review flowchart.

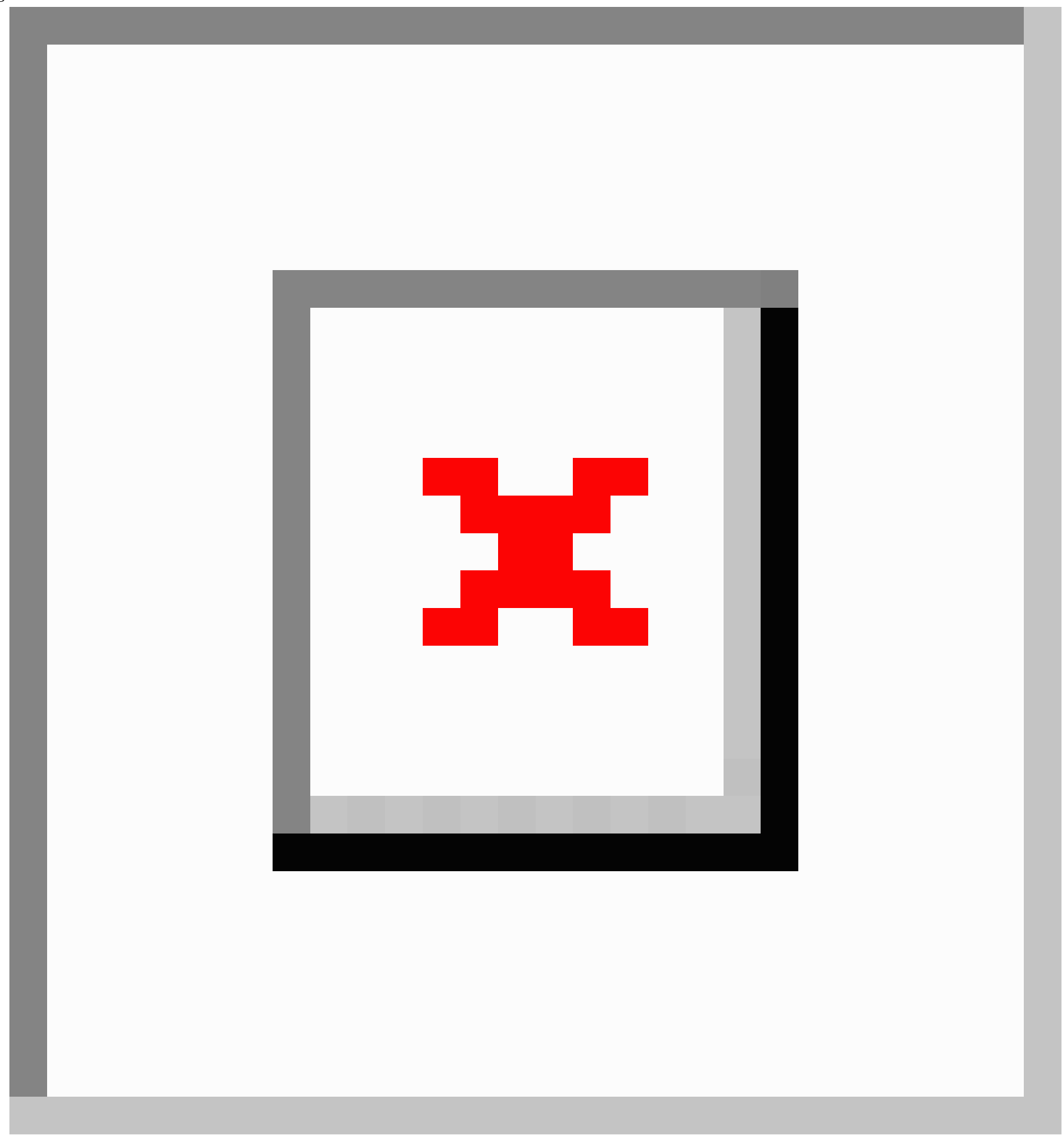


Table 1. Study characteristics.

\begin{tabular}{|c|c|c|}
\hline Variable & Description & Value \\
\hline Start of the experiment & Begins with the recruitment of the first patient. & $\begin{array}{l}\left.\text { Median: } 2006 \text { (IQR }{ }^{\mathrm{a}} 1999,2004\right) \\
\text { Unclear: } 40 \% \text { (51 studies) }\end{array}$ \\
\hline Country & Country where the experiment was carried out. & $\begin{array}{l}\text { Europe: } 50 \% \text { ( } 64 \text { studies) } \\
\text { United States: } 41 \% \text { (53 studies) } \\
\text { Canada: } 4 \% \text { (5 studies) } \\
\text { Australia: } 3 \% \text { (4 studies) } \\
\text { Asia: } 1.5 \% \text { (2 studies) }\end{array}$ \\
\hline Care context & $\begin{array}{l}\text { Location of the patients within their care pathway (after a hospitalization } \\
\text { for an acute episode or in stable condition, followed-up by a specialist } \\
\text { or a primary care provider). }\end{array}$ & $\begin{array}{l}\text { Post-acute hospitalization: } 75 \% \text { (96 studies) } \\
\text { Cardiology team: } 87 \% \text { (111 studies) }\end{array}$ \\
\hline Telemonitoring actors & $\begin{array}{l}\text { People directly involved in the telemonitoring service process (patients, } \\
\text { health care professionals, nurses, care givers, technicians). }\end{array}$ & $\begin{array}{l}\text { Patients: 100\% (128 studies) } \\
\text { Nurses: 86\% (110 studies) } \\
\text { Cardiologists: } 46 \% \text { (59 studies) } \\
\text { General physicians: } 26 \% \text { (33 studies) } \\
\text { Psychologists: } 4 \% \text { (5 studies) } \\
\text { Families: 4\% (5 studies) } \\
\text { Technicians: } 2.3 \% \text { (3 studies) }\end{array}$ \\
\hline Project lifecycle phase & $\begin{array}{l}\text { Four phases depict the lifecycle of a project: technical development } \\
\text { (prototype), clinical implementation (small scale experiment), integration } \\
\text { in the clinical pathway (large scale experiment), and routine patient care. }\end{array}$ & $\begin{array}{l}\text { Implementation: 59\% (76 studies) } \\
\text { Integration: } 20 \% \text { (26 studies) } \\
\text { Development: } 18 \% \text { (23 studies) } \\
\text { Routine care: } 0 \% \text { (no study) } \\
\text { Unclear: } 2.3 \% \text { (3 studies) }\end{array}$ \\
\hline Study design & $\begin{array}{l}\text { Methodological design of the study (randomized trial, cohort study, } \\
\text { cross-sectional study, etc). }\end{array}$ & $\begin{array}{l}\text { Randomized controlled trial: } 62 \% \text { (79 studies) } \\
\text { Cohort: } 34 \% \text { (43 studies) } \\
\text { Cross-sectional: } 3 \% \text { (4 studies) } \\
\text { Unclear: } 1.5 \% \text { ( } 2 \text { studies) }\end{array}$ \\
\hline Patient age & Mean age of included patients. & $\begin{array}{l}\text { Median: } 69 \text { (IQR 62.8, 74.2) years } \\
\text { Unclear: } 18 \% \text { ( } 23 \text { studies) }\end{array}$ \\
\hline Number of patients & Total number of subjects involved in the telemonitoring assessment. & $\begin{array}{l}\text { Patients: median } 157.5 \text { (IQR 71, 376) } \\
\text { Volunteers: median } 17 \text { (IQR 11, 24) } \\
\text { Unclear: } 6 \% \text { (7 studies) }\end{array}$ \\
\hline $\begin{array}{l}\text { Number of health care } \\
\text { professionals }\end{array}$ & $\begin{array}{l}\text { Total number of health care professionals involved in the telemonitoring } \\
\text { assessment. }\end{array}$ & $\begin{array}{l}\text { Care partners: median } 52 \text { (IQR 32, 82) } \\
\text { Nurses: median } 4 \text { (IQR 3,4) } \\
\text { Cardiologists: median } 13 \text { (IQR 6, 20) } \\
\text { Primary care physicians: median } 260 \text { (IQR 181, } \\
\text { 313) } \\
\text { Unclear: 92\% (118 studies) }\end{array}$ \\
\hline Associated interventions & $\begin{array}{l}\text { Interventions performed to enable the home telemonitoring service } \\
\text { (therapeutic education, training in equipment use, etc). }\end{array}$ & $\begin{array}{l}\text { Therapeutic education: } 32 \% \text { ( } 41 \text { studies) } \\
\text { Training of use of equipment: } 30 \% \text { (38 studies) } \\
\text { Informed family: } 4 \% \text { ( } 5 \text { studies) } \\
\text { Home nurse visit: } 2.3 \% \text { ( } 3 \text { studies) } \\
\text { Technical support: } 0.7 \% \text { (1 study) } \\
\text { Unclear: } 46 \% \text { (59 studies) }\end{array}$ \\
\hline Intervention duration & $\begin{array}{l}\text { Duration of the monitoring service per patient, from the first to the last } \\
\text { data transmission. }\end{array}$ & $\begin{array}{l}\text { Median: } 9 \text { (IQR 6,12) months } \\
\text { Unclear: } 10 \% \text { (13 studies) }\end{array}$ \\
\hline
\end{tabular}

${ }^{\mathrm{a}} \mathrm{IQR}$ : interquartile range. 
Textbox 1. Evaluation dimensions and related criteria.

Economic

- Costs of resource utilization: days in the hospital, number of nurse visits, number of consultations with cardiologist and general practitioner, number of emergency visits, hospitalization, and readmission rate

- $\quad$ Cost of technical development, deployment, and maintenance of the service

Clinical

- Patient-reported outcomes: quality of life, health status, functional capacity, and activities of daily living

- Disease-oriented outcomes: mortality rate and morbidity rate

- Patient adherence to treatment: diet and medication

- Physician-adherence to guidelines

Educational

- Patient knowledge of the disease

- $\quad$ Patient self-care knowledge and behavior

- Primary care physician education

- Familial caregiver involvement

Technical

- Ergonomics: intuitive functions and design, quick on/off switch, and setup and configuration of the system

- Characteristics: platform connection with other devices, authentication, secure storage, maintainability, and availability of service

User perspective

- Patient perception: feelings of patient, cognitive feedback, acceptability of technology and service, reliability of information and communication technology, willingness to pay, patient motivation, social network, self-efficacy and confidence, adaptation to telephone monitoring, ease of use, access to care providers, satisfaction with new technology, compliance with new technology, and overall satisfaction with the process of care

- Care provider perception: satisfaction, utility, acceptability of technology, ease of use, compliance with new technology, and overall satisfaction with the process of care

Organizational

- Administrative: insurance policy and hospital policy

- Clinical: acceptability of heart failure nurses by general physician, heart failure nurse/ physician communication, patient/physician communication, and physician workload

Table 2. Coverage of evaluation dimensions across studies and phases of the project lifecycle.

\begin{tabular}{|c|c|c|c|c|}
\hline \multirow[t]{2}{*}{ Dimension } & \multirow[t]{2}{*}{ Number of studies, n (\%) } & \multicolumn{3}{|l|}{ Lifecycle phase } \\
\hline & & Development $(\mathrm{n}=23), \mathrm{n}(\%)$ & Implementation $(\mathrm{n}=76), \mathrm{n}(\%)$ & Integration $(\mathrm{n}=26), \mathrm{n}(\%)$ \\
\hline Clinical & $107(84)$ & $11(48)$ & $68(89)$ & $23(88)$ \\
\hline Economic & $91(71)$ & $9(39)$ & $57(75)$ & $22(85)$ \\
\hline User perspective & $55(43)$ & $19(83)$ & $31(41)$ & $12(46)$ \\
\hline Educational & $18(14)$ & $3(13)$ & $10(13)$ & $5(19)$ \\
\hline Organizational & $7(5)$ & $1(4)$ & $5(7)$ & $1(4)$ \\
\hline Technical & $6(4)$ & $3(13)$ & $3(4)$ & $0(0)$ \\
\hline
\end{tabular}


Table 3. Evaluation criterion most frequently used in each dimension.

\begin{tabular}{|c|c|c|c|c|c|}
\hline \multirow[t]{2}{*}{ Criterion } & \multirow[t]{2}{*}{ Dimension } & \multirow{2}{*}{$\begin{array}{l}\text { Overall }(\mathrm{n}=128) \\
\mathrm{n}(\%)\end{array}$} & \multicolumn{3}{|l|}{ Lifecycle phase } \\
\hline & & & $\begin{array}{l}\text { Development } \\
(\mathrm{n}=23), \mathrm{n}(\%)\end{array}$ & $\begin{array}{l}\text { Implementation } \\
(\mathrm{n}=76), \mathrm{n}(\%)\end{array}$ & $\begin{array}{l}\text { Integration } \\
(\mathrm{n}=26), \mathrm{n}(\%)\end{array}$ \\
\hline Cost of resources utilization & Economic & $91(71)$ & $9(39)$ & $58(76)$ & $22(85)$ \\
\hline Quality of life & Clinical outcomes & $65(51)$ & $8(35)$ & $42(55)$ & $14(54)$ \\
\hline $\begin{array}{l}\text { Patient and family satisfaction with new } \\
\text { technology }\end{array}$ & User perspective & $21(16)$ & $7(30)$ & $10(13)$ & $3(12)$ \\
\hline Knowledge of disease & Educational outcomes & $14(11)$ & $3(13)$ & $8(10.5)$ & $4(15)$ \\
\hline Patient and physician communication & Organizational & $3(2.3)$ & $1(4)$ & $1(1.3)$ & $1(4)$ \\
\hline Reliability of transmitted data & Technical & $2(1.6)$ & $2(9)$ & $0(0)$ & $0(0)$ \\
\hline Device specifications & Technical & $2(1.6)$ & $2(9)$ & $0(0)$ & $0(0)$ \\
\hline
\end{tabular}

\section{Discussion}

We found 128 studies using a total of 52 evaluation criteria categorized into 6 high-level dimensions. No study covered all 6 evaluation dimensions. The evaluation dimensions were not used with the same frequency for all phases of the project lifecycle. The principle focus in the development phase was on user perspective, whereas the focus in the latter phases of the lifecycle was on the clinical and economical dimensions. The technical, organizational, and educational dimensions were poorly evaluated overall.

The 6 dimensions were derived from telemedicine assessment frameworks Grille d'Evaluation Multidisciplinaire Santé Autonomie (multidimensional evaluation grid for health and autonomy) [12], model for assessment of telemedicine [13], Khoja-Durrani-Scott evaluation framework [14], Technologique, Ergonomique, Médicale, Sociale, Économique et Déontologique (technological, ergonomic, medical, social, economic, and ethical) [15], and the 3-dimensional model [16]. These frameworks required adaptations to better fit telemonitoring. First, the role of patients and nurses is prominent in telemonitoring projects, whereas it is more limited in teleconsultation and tele-expertise. Thus, smooth collaboration must be ensured and evaluated between patients and care providers as much as between care providers themselves. Specific organizational and educational evaluation criteria are therefore needed for telemonitoring. Second, telemonitoring stands out from a technical point of view because devices are needed to gather data. The ergonomic assessment, user perception, and technical characteristics of these devices are thus key elements in the assessment of telemonitoring projects [15].

Previous evaluation frameworks are not adapted to all phases of a telemonitoring project lifecycle and do not take into account the perspective of all telemonitoring actors and external stakeholders (manufacturers, payers, etc). For example, a telemonitoring project at the first phase of its lifecycle (pilot) cannot appropriately evaluate clinical outcomes and, at the other end, proper technical evaluation is a prerequisite long before the last phase of a telemonitoring project lifecycle (routine clinical care). Criteria and indicators for a given dimension will differ across lifecycle phases. For example, the user perspective should be evaluated in all 4 phases but with different criteria: "ease of use of the system" is an appropriate criterion in the development phase, "satisfaction with new technology" in the implementation and integration phases, and "overall satisfaction with the process of care" in routine clinical care.

This review is limited by its focus on noninvasive HF telemonitoring. However, aside from disease-specific clinical outcomes, noninvasive telemonitoring services share many technical, economic, organizational, and educational features independently of the target disease. Our framework should therefore be easy to adapt to other health conditions. Our search strategy may have missed some studies that were described by other keywords. However, we found only 7 additional studies in 3 recent Cochrane reviews [18-20]. The number of missing studies is therefore likely to be low. Our 52 criteria cover all outcomes reported in previous systematic reviews on the evaluation of telemonitoring in $\mathrm{HF}[18,25]$ but also in other chronic diseases, such as diabetes and chronic obstructive pulmonary diseases $[19,20]$. We have identified broad evaluation dimensions from previously published evaluation frameworks for telemedicine projects and refined these dimensions iteratively during the review process. The 6 final dimensions accommodate all evaluation criteria used in previously published evaluation studies, but other categorization schemes are certainly possible and should be compared. The data and methods used in this review were not suited to assess the strength, limitations, relevance, and usefulness of each retrieved evaluation criterion. A follow-up to our work is needed to provide more guidance for the use of criteria in future HF telemonitoring evaluation studies.

Comprehensive telemonitoring evaluation frameworks should cover all 6 dimensions and help users choose the appropriate dimensions and evaluation criteria depending on the phase of their telemonitoring project lifecycle and the perspective of telemonitoring actors or external stakeholders they want to adopt. Our next goal is to build such a framework for noninvasive HF telemonitoring, deliberately emphasizing the technical, organizational, and educational dimensions that have been neglected by previous telemonitoring assessment studies. We will test this framework on an ongoing HF telemonitoring project. 


\section{Acknowledgments}

This work was supported by the Regional Health Agency of Centre Val de Loire and the French National Association of Technical Research (ANRT).

\section{Conflicts of Interest}

None to declare.

\section{Multimedia Appendix 1}

Bibliographic search strategy.

[PDF File (Adobe PDF File), 16KB-Multimedia Appendix 1]

\section{Multimedia Appendix 2}

Collected study characteristics.

[PDF File (Adobe PDF File), 18KB-Multimedia Appendix 2]

\section{Multimedia Appendix 3}

Included papers reference list.

[PDF File (Adobe PDF File), 965KB-Multimedia Appendix 3]

\section{Multimedia Appendix 4}

Detailed study characteristics.

[XLS File (Microsoft Excel File), 181KB-Multimedia Appendix 4]

\section{Multimedia Appendix 5}

Number of evaluation dimensions covered per study.

[PPT File (Microsoft PowerPoint Presentation), 124KB-Multimedia Appendix 5]

\section{Multimedia Appendix 6}

Number of evaluation criteria used per study.

[PPT File (Microsoft PowerPoint Presentation), 138KB-Multimedia Appendix 6]

\section{Multimedia Appendix 7}

Collected study characteristics.

[PDF File (Adobe PDF File), 18KB-Multimedia Appendix 7]

\section{References}

1. Cook C, Cole G, Asaria P, Jabbour R, Francis DP. The annual global economic burden of heart failure. Int J Cardiol 2014 Feb 15;171(3):368-376. [doi: 10.1016/j.ijcard.2013.12.028] [Medline: 24398230]

2. Ambrosy AP, Fonarow GC, Butler J, Chioncel O, Greene SJ, Vaduganathan M, et al. The global health and economic burden of hospitalizations for heart failure: lessons learned from hospitalized heart failure registries. J Am Coll Cardiol 2014 Apr 01;63(12):1123-1133 [FREE Full text] [doi: 10.1016/j.jacc.2013.11.053] [Medline: 24491689]

3. Berry C, Murdoch D, McMurray J. Economics of chronic heart failure. Eur J Heart Fail 2001 Jun;3(3):283-291 [FREE Full text] [Medline: 11377998]

4. Smith B, Forkner E, Zaslow B, Krasuski RA, Stajduhar K, Kwan M, et al. Disease management produces limited quality-of-life improvements in patients with congestive heart failure: evidence from a randomized trial in community-dwelling patients. Am J Manag Care 2005 Nov;11(11):701-713 [FREE Full text] [Medline: 16268753]

5. Louis A, Turner T, Gretton M, Baksh A, Cleland J. A systematic review of telemonitoring for the management of heart failure. Eur J Heart Fail 2003 Oct;5(5):583-590 [FREE Full text] [Medline: 14607195]

6. Meystre S. The current state of telemonitoring: a comment on the literature. Telemed J E Health 2005 Feb;11(1):63-69. [doi: $10.1089 / \mathrm{tmj} .2005 .11 .63]$ [Medline: 15785222] 
7. Chaudhry SI, Phillips CO, Stewart SS, Riegel B, Mattera JA, Jerant AF, et al. Telemonitoring for patients with chronic heart failure: a systematic review. J Card Fail 2007 Feb;13(1):56-62 [FREE Full text] [doi: 10.1016/j.cardfail.2006.09.001] [Medline: 17339004$]$

8. Ramaekers B, Janssen-Boyne J, Gorgels A, Vrijhoef H. Adherence among telemonitored patients with heart failure to pharmacological and nonpharmacological recommendations. Telemed J E Health 2009;15(6):517-524. [doi:

10.1089/tmj.2009.0160] [Medline: 19566401]

9. Kotb A, Cameron C, Hsieh S, Wells G. Comparative effectiveness of different forms of telemedicine for individuals with heart failure (HF): a systematic review and network meta-analysis. PLoS One 2015;10(2):e0118681 [FREE Full text] [doi: 10.1371/journal.pone.0118681] [Medline: 25714962]

10. Cowie M, Bax J, Bruining N, Cleland J, Koehler F, Malik M, et al. e-Health: a position statement of the European Society of Cardiology. Eur Heart J 2016 Jan 01;37(1):63-66. [doi: 10.1093/eurheartj/ehv416] [Medline: 26303835]

11. Schwamm L, Chumbler N, Brown E, Fonarow G, Berube D, Nystrom K, American Heart Association Advocacy Coordinating Committee. Recommendations for the Implementation of Telehealth in Cardiovascular and Stroke Care: A Policy Statement From the American Heart Association. Circulation 2017 Feb 14;135(7):e24-e44 [FREE Full text] [doi: 10.1161/CIR.0000000000000475] [Medline: 27998940]

12. Le Goff-Pronost M, Picard R. Need for ICTs assessment in the health sector: a multidimensional framework. Commun Strateg 2011;83(3):87-108 [FREE Full text]

13. Kidholm K, Ekeland A, Jensen L, Rasmussen J, Pedersen C, Bowes A, et al. A model for assessment of telemedicine applications: MAST. Int J Technol Assess Health Care 2012 Jan;28(1):44-51. [doi: 10.1017/S0266462311000638] [Medline: $\underline{2617736]}$

14. Khoja S, Durrani H, Scott R, Sajwani A, Piryani U. Conceptual framework for development of comprehensive e-health evaluation tool. Telemed J E Health 2013 Jan;19(1):48-53. [doi: 10.1089/tmj.2012.0073] [Medline: 22957502]

15. Fouquet Y, Sablier J, Vuillerme N, Daynes P, Rialle V. TEMSED: une approche multicritère d'évaluation des technologies de télésanté et d'autonomie. Ann Phys Rehabil Med 2011 Oct;54(supplement 1):e57. [doi: 10.1016/j.rehab.2011.07.776]

16. Bashshur R, Shannon G, Sapci H. Telemedicine evaluation. Telemed J E Health 2005 Jun;11(3):296-316. [doi: 10.1089/tmj.2005.11.296] [Medline: 16035928 ]

17. Gurné O, Conraads V, Missault L, Mullens W, Vachierys J, Van Meighem W, et al. A critical review on telemonitoring in heart failure. Acta Cardiol 2012 Aug;67(4):439-444. [Medline: 22997998]

18. Inglis S, Clark R, Dierckx R, Prieto-Merino D, Cleland J. Structured telephone support or non-invasive telemonitoring for patients with heart failure. Cochrane Database Syst Rev 2015;10:CD007228. [doi: 10.1002/14651858]

19. Posadzki P, Mastellos N, Ryan R, Gunn LH, Felix LM, Pappas Y, et al. Automated telephone communication systems for preventive healthcare and management of long-term conditions. Cochrane Database Syst Rev 2016 Dec 14;12:CD009921. [doi: 10.1002/14651858.CD009921.pub2] [Medline: 27960229]

20. Flodgren G, Rachas A, Farmer AJ, Inzitari M, Shepperd S. Interactive telemedicine: effects on professional practice and health care outcomes. Cochrane Database Syst Rev 2015;9:CD002098. [doi: 10.1002/14651858.CD002098.pub2] [Medline: 26343551]

21. Benatar D, Bondmass M, Ghitelman J, Avitall B. Outcomes of Chronic Heart Failure. Arch Intern Med 2003 Feb 10;163(3):347-352. [doi: 10.1001/archinte.163.3.347] [Medline: 12578516]

22. Ferrante D, Varini S, Macchia A, Soifer S, Badra R, Nul D, et al. Long-term results after a telephone intervention in chronic heart failure: DIAL (Randomized Trial of Phone Intervention in Chronic Heart Failure) follow-up. J Am Coll Cardiol 2010 Jul 27;56(5):372-378 [FREE Full text] [doi: 10.1016/j.jacc.2010.03.049] [Medline: 20650358]

23. Giordano A, Zanelli E, Scalvini S. Home-based telemanagement in chronic heart failure: an 8-year single-site experience. J Telemed Telecare 2011;17(7):382-386. [doi: 10.1258/jtt.2011.110201] [Medline: 21979603]

24. Cleland JGF, Louis AA, Rigby AS, Janssens U, Balk AHMM. Noninvasive home telemonitoring for patients with heart failure at high risk of recurrent admission and death: the Trans-European Network-Home-Care Management System (TEN-HMS) study. J Am Coll Cardiol 2005 May 17;45(10):1654-1664 [FREE Full text] [doi: 10.1016/j.jacc.2005.01.050] [Medline: $\underline{15893183}$ ]

25. Kitsiou S, Paré G, Jaana M. Effects of home telemonitoring interventions on patients with chronic heart failure: an overview of systematic reviews. J Med Internet Res 2015 Mar;17(3):e63 [FREE Full text] [doi: 10.2196/jmir.4174] [Medline: $\underline{25768664]}$

\section{Abbreviations}

EMBASE: Excerpta Medica database

HF: heart failure

MEDLINE: Medical Literature Analysis and Retrieval System Online 
Edited by G Eysenbach; submitted 26.04.17; peer-reviewed by S Agboola, JB Park; comments to author 12.07.17; revised version received 18.10.17; accepted 20.11.17; published 16.01.18

Please cite as:

Farnia T, Jaulent MC, Steichen $O$

Evaluation Criteria of Noninvasive Telemonitoring for Patients With Heart Failure: Systematic Review

$J$ Med Internet Res 2018;20(1):e16

URL: http://www.jmir.org/2018/1/e16/

doi: 10.2196/jmir.7873

PMID: 29339348

(C)Troskah Farnia, Marie-Christine Jaulent, Olivier Steichen. Originally published in the Journal of Medical Internet Research (http://www.jmir.org), 16.01.2018. This is an open-access article distributed under the terms of the Creative Commons Attribution License (https://creativecommons.org/licenses/by/4.0/), which permits unrestricted use, distribution, and reproduction in any medium, provided the original work, first published in the Journal of Medical Internet Research, is properly cited. The complete bibliographic information, a link to the original publication on http://www.jmir.org/, as well as this copyright and license information must be included. 